\section{Chromatin immunoprecipitaion}

We grew yeast cells to $A_{600} \sim 1$ in YEPD or low phosphate-YEPD ${ }^{25}$ medium and performed Chr-IP as described elsewhere, using highly specific antibodies raised against individual sites of acetylation and tested in Chr-IP against the relevant histone mutations ${ }^{5,27}$ (N.S. and M.G., unpublished data). We fragmented DNA in chromatin to $\sim 500$ bp by sonication. We performed immunoprecipitations with the addition of $5 \mu \mathrm{l}$ of each antiserum specific for each acetyl-lysine to $50 \mu \mathrm{l}$ of whole-cell extract from $8 \times 10^{7}$ cells. We used $1 / 100$ of the immunoprecipitated DNA for analysis by PCR. We performed PCR in the linear range of amplification for each primer set and DNA sample, and added $0.8 \mu \mathrm{Ci} \mu l^{-1}\left[\alpha-{ }^{32} \mathrm{P}\right] \mathrm{dATP}$ (specific activity of $3,000 \mathrm{Ci} \mathrm{mmol}^{-1}$ ) to each PCR reaction. We quantified the data using PhosphorImager and ImageQuant (Molecular Dynamics).

\section{Strains}

Histone acetylase/deacetylase mutants WJY110 ( $\Delta$ hda1), WJY139 ( $\Delta$ gcn5), WJY140 $(\Delta r p d 3)$, WJY141 ( $\Delta h d a 1 \Delta r p d 3)$, WJY142 $(\Delta h d a 1 \Delta g c n 5)$ and WJY143 $(\Delta r p d 3 \Delta g c n 5)$ (J.W. and M.G., unpublished data) are all isogenic to YDS2 (ref. 29). LPY3431 (wild type) and LPY3430 (esa1-L327S) ${ }^{19}$ were provided by L. Pillus. RPD3 was deleted in these strain using the $r p d 3:: L E U 2$ disruption plasmid $\mathrm{pMVL}^{17}$ to produce strains MVY006 $(\Delta r p d 3)$ and MVY007 ( $\Delta r p d 3 e s a 1-L 327 S)$. We confirmed the disruption by PCR.

Received 29 August; accepted 3 October 2000.

1. Georgakopoulos, T. \& Thireos, G. Two distinct yeast transcriptional activators require the function of the GCN5 protein to promote normal levels of transcription. EMBO J. 11, 4145-4152 (1992).

2. Brownell, J. E. et al. Tetrahymena histone acetyltransferase A: a homolog to yeast Gcn5p linking histone acetylation to gene activation. Cell 84, 843-851 (1996).

3. Drysdale, C. M. et al. The Gen4p activation domain interacts specifically in vitro with RNA polymerase II holoenzyme, TFIID, and the Adap-Gcn5p coactivator complex. Mol. Cell. Biol. 18, 1711-1724 (1998)

4. Kadosh, D. \& Struhl, K. Targeted recruitment of the Sin3-Rpd3 histone deacetylase complex generate a highly localized domain of repressed chromatin in vivo. Mol. Cell. Biol. 18, 5121-5127 (1998).

5. Rundlett, S. E., Carmen, A. A., Suka, N., Turner, B. M. \& Grunstein, M. Transcriptional repression by UME6 involves deacetylation of lysine 5 of histone H4 by RPD3. Nature 392, 831-835 (1998).

6. Knoepfler, P. S. \& Eisenman, R. N. Sin meets NuRD and other tails of repression. Cell 99, 447-450 (1999).

7. Vidal, M. \& Gaber, R. F. RPD3 encodes a second factor required to achieve maximum positive and negative transcriptional states in Saccharomyces cerevisiae. Mol. Cell. Biol. 11, 6317-6327 (1991)

8. Svaren, J. \& Hörz, W. Transcription factors vs nucleosomes: regulation of the $\mathrm{PHO} 5$ promoter in yeast. Trends Biochem. Sci. 22, 93-97 (1997)

9. Han, M. \& Grunstein, M. Nucleosome loss activates yeast downstream promoters in vivo. Cell 55, $1137-1145$ (1988)

10. Gregory, P. D. et al. Absence of Gcn5 HAT activity defines a novel state in the opening of chromatin a the PHO5 promoter in yeast. Mol. Cell 1, 495-505 (1998)

11. Solomon, M. J. \& Varshavsky, A. Formaldehyde-mediated DNA-protein crosslinking: a probe for in vivo chromatin structures. Proc. Natl Acad. Sci. USA 82, 6470-6474 (1985).

12. Orlando, V., Strutt, H. \& Paro, R. Analysis of chromatin structure by in vivo formaldehyde crosslinking. Methods 11, 205-214 (1997).

13. Braunstein, M., Rose, A. B., Holmes, S. G., Allis, C. D. \& Broach, J. R. Transcriptional silencing in yeas is associated with reduced nucleosome acetylation. Genes Dev. 7, 592-604 (1993).

14. Dedon, P. C., Soults, J. A., Allis, C. D. \& Gorovsky, M. A. A simplified formaldehyde fixation and immunoprecipitation technique for studying protein-DNA interactions. Anal. Biochem. 197, 83-90 (1991).

15. Hecht, A., Strahl-Bolsinger, S. \& Grunstein, M. Spreading of transcriptional repressor SIR3 from telomeric heterochromatin. Nature 383, 92-96 (1996).

16. Kuo, M. H., Zhou, J., Jambeck, P., Churchill, M. E. \& Allis, C. D. Histone acetyltransferase activity of yeast Gcn5p is required for the activation of target genes in vivo. Genes Dev. 12, 627-639 (1998).

17. Rundlett, S. E. et al. HDA1 and RPD3 are members of distinct yeast histone deacetylase complexes that regulate silencing and transcription. Proc. Natl Acad. Sci. USA 93, 14503-14508 (1996).

18. Grant, P. A. et al. Expanded lysine acetylation specificity of Gen5 in native complexes. J. Biol. Chem. 274, 5895-5900 (1999)

19. Clarke, A. S., Lowell, J. E., Jacobson, S. J. \& Pillus, L. Esalp is an essential histone acetyltransferase required for cell cycle progression. Mol. Cell. Biol. 19, 2515-2526 (1999).

20. Wittschieben, B. O. et al. A novel histone acetyltransferase is an integral subunit of elongating RNA polymerase II holoenzyme. Mol. Cell 4, 123-128 (1999).

21. Reifnyder, C., Lowell, J., Clarke, A. \& Pillus, L. Yeast SAS silencing genes and human genes associated with AML and HIV-1 Tat interactions are homologous with acetyltransferases. Nature Genet. 16, 109 (1997).

22. Ehrenhofer-Murray, A. E., Rivier, D. H. \& Rine, J. The role of Sas2, an acetyltransferase homologue of Saccharomyces cerevisiae, in silencing and ORC function. Genetics 145, 923-934 (1997)

23. Parthun, M. R., Widom, J. \& Gottschling, D. E. The major cytoplasmic histone acetyltransferase in yeast: links to chromatin replication and histone metabolism. Cell 87, 85-94 (1996).

24. Hughes, T. R. et al. Functional discovery via a compendium of expression profiles. Cell 102, 109-126 (2000).

25. Han, M., Kim, U. J., Kayne, P. \& Grunstein, M. Depletion of histone H4 and nucleosomes activates the PHO5 gene in Saccharomyces cerevisiae. EMBO J. 7, 2221-2228 (1988).

26. Schmitt, M. E., Brown, T. A. \& Trumpower, B. L. A rapid and simple method for preparation of RNA from Saccharomyces cerevisiae. Nucleic Acids Res. 18, 3091-3092 (1990).

27. Hecht, A. \& Grunstein, M. Mapping DNA interaction sites of chromosomal proteins using immunoprecipitation and polymerase chain reaction. Methods Enzymol. 304, 399-414 (1999).
28. Almer, A., Rudolph, H., Hinnen, A. \& Hörz, W. Removal of positioned nucleosomes from the yeast $\mathrm{PHO} 5$ promoter upon $\mathrm{PHO} 5$ induction releases additional upstream activating DNA elements. EMBO J. 5, 2689-2696 (1986).

29. Laman, H., Balderes, D. \& Shore, D. Disturbance of normal cell cycle progression enhances the establishment of transcriptional silencing in Saccharomyces cerevisiae. Mol. Cell. Biol. 15, 3608-3617 (1995)

\section{Acknowledgements}

We thank L. Pillus for the $e s a 1^{\text {ts }}$ strain. We are grateful to the members of the Grunstein laboratory for critical comments and discussions throughout this work and are thankful to Y. Suka and A. Carmen for antibodies against histone sites of acetylation. M.V. acknowledges pre-doctoral support from the Dottorato di Ricerca in Genetica e Biologia Molecolare-Università degli Studi di Roma "la Sapienza". This work was supported by a Public Health Service grant from the National Institutes of Health.

Correspondence and requests for materials should be addressed to M.G. (e-mail: mg@mbi.ucla.edu).

\title{
An intrinsic but cell-nonautonomous defect in GATA-1-overexpressing mouse erythroid cells
}

David Whyatt, Fokke Lindeboom, Alar Karis, Rita Ferreira, Eric Milot, Rudi Hendriks, Marella de Bruijin, An Langeveld, Joost Gribnau, Frank Grosveld \& Sjaak Philipsen

Nature 406, 519-524 (2000).

In Fig. 2d, GATA-1 tg. Btk ${ }^{\text {lacZl+ }}$ females should have been numbered 1 to 3 ; in Fig. 3a, the last sample should have been marked G4ch no. 14; and in Fig. 4b, the last class of animal should have been tg. female.

\section{correction}

\section{Id2 is a retinoblastoma protein target and mediates signalling by Myc oncoproteins}

\section{Anna Lasorella, Michela Noseda, Mercedes Beyna, Yoshifumi Yokota \& Antonio lavarone}

Nature 407, 592-598 (2000).

The name of one author, Yoshifumi Yokota, was inadvertently omitted from the author list but is included above. He is affiliated with the Department of Biochemistry, Fukui Medical University, Fukui, Japan. 
once axons of $\mathrm{Lhx} 3^{+}$motor neurons have bypassed axial muscle targets they continue to grow along $\mathrm{Lhx}^{-}$pathways, lending further support to the notion that the passive deployment activity of motor axons is quite robust ${ }^{12-16}$. Indeed, this passive activity combined with epigenetic interactions raises the possibility that knockouts of guidance receptors could appear to have all nerves in place, despite an erosion of specificity for targets. An ability to extend axons passively seems incongruous with the highly specific pathfinding observed for motor neurons ${ }^{2}$. Our findings suggest an additional mechanism that may cooperate with guidance receptors to establish specific motor connections. In principle, the occupancy of a pathway could increase the relative barrier for inappropriate motor axons, thus magnifying the actions of guidance receptors and enhancing the fidelity of pathfinding.

\section{Methods}

A 9-kilobase fragment of the upstream region of $H B 9$ (ref. 19) was linked to complementary DNAs encoding $n L a c Z, L h x 1$ or $L h x 3$. At the start methionine a lox-neomycinlox cassette was inserted such that translation could occur following Cre-mediated DNA recombination at the lox sites. Promoter constructs were targeted by homologous recombination into the $3^{\prime}$-untranslated region of Isl2.

To generate aggregation chimaeras $\mathrm{TgH}$ Isl $2^{\mathrm{HBP} \text { :LNL:Lhx } 3} / \mathrm{TgN}^{\mathrm{Pro}: \mathrm{CRE}} \mathrm{F} 1$ males were crossed to superovulated ROSA26 (ref. 26) females. Morula stage embryos were flushed, stripped of the Zona and aggregated to wild-type morula embryos, transferred into pseudopregnant females and recovered at E13.5 for analysis.

Immunocytochemistry, in situ hybridization and neuronal labelling were performed as described $\mathrm{d}^{3,17,19,27}$

Received 22 February; accepted 22 May 2000

1. Tanabe, Y. \& Jessell, T. M. Diversity and pattern in the developing spinal cord. Science 274, 1115-1122 (1996).

2. Landmesser, L. The development of motor projection patterns in the chick hind limb. J. Physiol. (Lond.) 284, 391-414 (1978).

3. Tsuchida, T. et al. Topographic organization of embryonic motor neurons defined by expression of LIM homeobox genes. Cell 79, 957-970 (1994).

4. Varela-Echavarria, A., Pfaff, S. L. \& Guthrie, S. Differential expression of LIM homeobox genes amon motor neuron subpopulations in the developing chick brain stem. Mol. Cell. Neurosci. 8, 242-257 (1996).

. Appel, B. et al. Motoneuron fate specification revealed by patterned LIM homeobox gene expression in embryonic zebrafish. Development 121, 4117-4125 (1995).

6. Jurata, L. W., Thomas, J. B. \& Pfaff, S. L. Transcriptional mechanisms in the development of motor control. Curr. Opin. Neurobiol. 10, 72-79 (2000).

7. Pfaff, S. \& Kintner, C. Neuronal diversification: development of motor neuron subtypes. Curr. Opin. Neurobiol. 8, 27-36 (1998).

8. Bell, E., Wingate, R. J. \& Lumsden, A. Homeotic transformation of rhombomere identity after localized Hoxb1 misexpression. Science 284, 2168-2171 (1999).

9. Ferguson, B. A. Development of motor innervation of the chick following dorsal-ventral limb bud rotations. J. Neurosci. 3, 1760-1772 (1983).

10. Lance-Jones, C. \& Landmesser, L. Motoneurone projection patterns in the chick hind limb following partial reversals of the spinal cord. J. Physiol. 302, 581-602 (1980).

11. Ferns, M. J. \& Hollyday, M. Motor innervation of dorsoventrally reversed wings in chick/quail chimeric embryos. J. Neurosci. 13, 2463-2476 (1993).

12. Summerbell, D. \& Stirling, R. V. The innervation of dorsoventrally reversed chick wings: evidence that motor axons do not actively seek out their appropriate targets. J. Embryol. Exp. Morphol. 61, 233-247 (1981).

13. Straznicky, C. The patterns of innervation and movements of ectopic hindlimb supplied by brachial spinal cord segments in the chick. Anat. Embryol. (Berl.) 167, 247-262 (1983).

14. Lance-Jones, C. C. Motoneuron projection patterns in chick embryonic limbs with a double complement of dorsal thigh musculature. Dev. Biol. 116, 387-406 (1986).

15. Whitelaw, V. \& Hollyday, M. Position-dependent motor innervation of the chick hindlimb following serial and parallel duplications of limb segments. J. Neurosci. 3, 1216-1225 (1983).

16. O'Brien, M. K., Landmesser, L. \& Oppenheim, R. W. Development and survival of thoracic motoneurons and hindlimb musculature following transplantation of the thoracic neural tube to the lumbar region in the chick embryo: functional aspects. J. Neurobiol. 21, 341-355 (1990).

17. Sharma, K. et al. LIM homeodomain factors Lhx3 and Lhx4 assign subtype identities for motor neurons. Cell 95, 817-828 (1998)

18. Arber, S. et al. Requirement for the homeobox gene $\mathrm{Hb} 9$ in the consolidation of motor neuron identity. Neuron 23, 659-674 (1999).

19. Thaler, J. et al. Active suppression of interneuron programs within developing motor neurons revealed by analysis of homeodomain factor HB9. Neuron 23, 675-687 (1999).

20. O'Gorman, S., Dagenais, N. A., Qian, M. \& Marchuk, Y. Protamine-Cre recombinase transgenes efficiently recombine target sequences in the male germ line of mice, but not in embryonic stem cells. Proc. Natl Acad. Sci. USA 94, 14602-14607 (1997).

21. Wetts, R. \& Vaughn, J. E. Choline acetyltransferase and NADPH diaphorase are co-expressed in rat spinal cord neurons. Neuroscience 63, 1117-1124 (1994).

22. Lin, J. H. et al. Functionally related motor neuron pool and muscle sensory afferent subtypes defined by coordinate ETS gene expression. Cell 95, 393-407 (1998).

23. Lance-Jones, C. \& Landmesser, L. Motoneurone projection patterns in embryonic chick limbs following partial deletions of the spinal cord. J. Physiol. (Lond.) 302, 559-580 (1980).

24. Goodhill, G. J. \& Richards, L. J. Retinotectal maps: molecules, models and misplaced data. Trends Neurosci. 22, 529-534 (1999).
25. Thor, S., Andersson, S. G., Tomlinson, A. \& Thomas, J. B. A LIM-homeodomain combinatorial code for motor-neuron pathway selection. Nature 397, 76-80 (1999).

26. Friedrich, G. \& Soriano, P. Promoter traps in embryonic stem cells: a genetic screen to identify and mutate developmental genes in mice. Genes Dev. 5, 1513-1523 (1991).

27. Pfaff, S. L., Mendelsohn, M., Stewart, C. L., Edlund, T. \& Jessell, T. M. Requirement for LIM homeobox gene Isl1 in motor neuron generation reveals a motor neuron-dependent step in interneuron differentiation. Cell 84, 309-320 (1996).

\section{Acknowledgements}

We thank A. Joyner and A. Auerbach for the training to generate chimaeric embryos: M. McLean for help with immunocytochemistry; S. O'Gorman for Cre mice and the loxneo-lox cassette; B. Hogan for Lhx1; H. Westphal for Lhx3; L. Jurata, C. Lance-Jones, G. Lemke and J. Thomas; and J. Thaler for insightful comments on the manuscript. This work derives from initial studies on LIM genes while S.L.P. was a fellow with T. Jessell. The Human Frontiers Science Program provided postdoctoral support for K. S., and the National Institutes of Health provided training support for A.E.L. This research was funded by the National Institutes of Health. S.L.P. is a Basil O'Connor, McKnight, Pew, and Alfred P. Sloan Scholar.

Correspondence and requests for materials should be addressed to S.L.P. (e-mail: Pfaff@Salk.edu).

\section{An intrinsic but cell-nonautonomous defect in GATA-1-overexpressing mouse erythroid cells}

\author{
David Whyatt*, Fokke Lindeboom $\dagger$, Alar Karis $\dagger$, Rita Ferreira $\dagger$, \\ Eric Milot $\dagger$, Rudi Hendriks $\dagger$, Marella de Brujjn $\dagger$, An Langeveld $\dagger$, \\ Joost Gribnau $\dagger$, Frank Grosveld $\dagger$ \& Sjaak Philipsen $\dagger$
}

* Division of Molecular Carcinogenesis, The Netherlands Cancer Institute, 1066 CX Amsterdam, The Netherlands

$\dagger$ Erasmus University, Department of Cell Biology and Genetics,

Medical Genetics Centre, PO Box 1738, 3000 DR Rotterdam, The Netherlands

GATA-1 is a tissue-specific transcription factor that is essential for the production of red blood cells ${ }^{1,2}$. Here we show that overexpression of GATA-1 in erythroid cells inhibits their differentiation, leading to a lethal anaemia. Using chromosome-Xinactivation of a GATA-1 transgene and chimaeric animals, we show that this defect is intrinsic to erythroid cells, but nevertheless cell nonautonomous. Usually, cell nonautonomy is thought to reflect aberrant gene function in cells other than those that exhibit the phenotype ${ }^{3}$. On the basis of our data, we propose an alternative mechanism in which a signal originating from wild-type erythroid cells restores normal differentiation to cells overexpressing GATA-1 in vivo. The existence of such a signalling mechanism indicates that previous interpretations of cell-nonautonomous defects may be erroneous in some cases and may in fact assign gene function to incorrect cell types.

GATA-1 expression is required at the relatively immature proerythroblast stage $^{1,2}$, as GATA-1 null proerythroblasts undergo apoptosis $^{4}$ and reduced GATA-1 levels inhibit proerythroblast differentiation ${ }^{5}$. However, the role of GATA-1 later in erythroid differentiation remains obscure. Murine erythroleukaemia (MEL) cells overexpressing GATA-1 under the control of the erythroidspecific human $\beta$-globin locus control region linked to the $\beta$-globin promoter (construct PEV3-GATA-1) fail to activate the expression of differentiation markers in response to the chemical inducer dimethyl sulphoxide (DMSO) and do not undergo differentiation-associated proliferative arrest ${ }^{6}$. Embryonic stem (ES) cell clones overexpressing GATA-1 also generate erythroid colonies that are inhibited in terminal differentiation ${ }^{6}$. Furthermore, overexpression of an inducible GATA-1 fusion protein (GATA-1-LBD, containing the tamoxifen-inducible ligand-binding domain of the 
oestrogen receptor) also inhibits erythroid differentiation (R.F. and D.W., unpublished data). These results may explain our failure to produce a transgenic line of mice by conventional microinjection of PEV3-GATA-1, because loss of erythroid differentiation would be lethal in vivo.

We therefore exploited the process of $\mathrm{X}$-inactivation ${ }^{7}$, as an $\mathrm{X}$ linked GATA-1 transgene should be transcriptionally active in 50\% of female erythroid precursors. In males, X-inactivation does not occur, and all erythroid cells should overexpress GATA-1. Mice can survive to term when $50 \%$ of erythroid precursors fail to differentiate normally, for example in females with one disrupted GATA1 allele (which is X-linked); however, roughly 30\% of GATA- 1 null heterozygous females die from severe anaemia by 15.5 days post coitus (d.p.c.). In survivors, anaemia is transient and recovery is thought to be due to in vivo selection of normal progenitors ${ }^{8,9}$.

DNA fluorescence-in-situ-hybridization (FISH) screening of male ES cells stably transfected with PEV3-GATA-1 showed localization of the transgene to the X chromosome in clone G4. The expected ratio in male to female progeny (38:34) was observed from $100 \%$ germline transmitting male chimaeras generated from this clone, $\mathrm{F}_{1}$ females carrying the transgene and $\mathrm{F}_{1}$ males (except one)

a

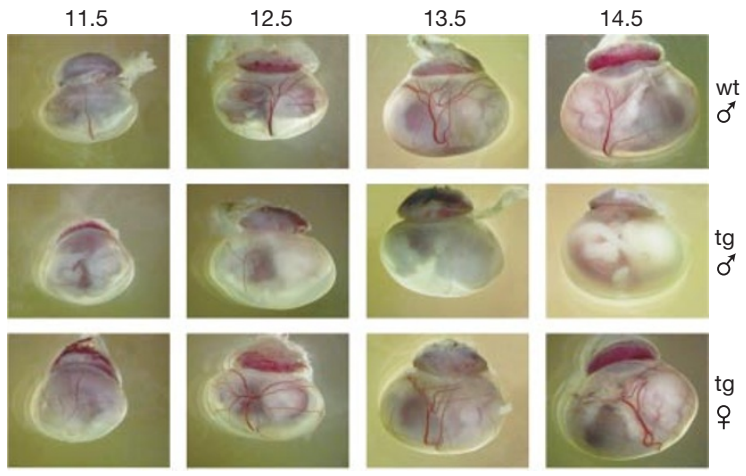

b

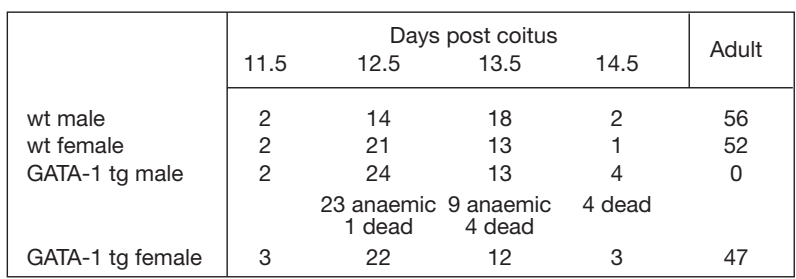

c
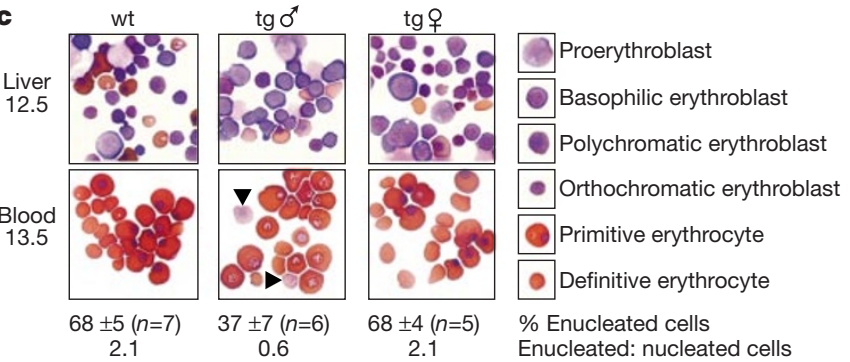

Figure 1 GATA-1 overexpression in vivo. a, Representative wild-type (wt) males and transgenics (tg) of either sex, 11.5 d.p.c. to 14.5 d.p.c., yolk sacs intact. b, Genotype and phenotype of embryos and adults, excluding $F_{1}$. Death was defined by lack of heartbeat, pallor was scored by anaemia. c, Disaggregated 12.5-d.p.c. fetal liver and 13.5-d.p.c. blood. Indicated by key is morphology of differentiating erythroid precusors and erythrocytes. Arrowheads indicate erythroid precusors in male transgenic blood $(<3 \%$ of all cells). Percentage of enucleated erythrocytes ( $>300$ events per embryo), number ( $n$ ) of independent embryos and standard deviations, and ratio of enucleated to nucleated erythroid cells are shown below.
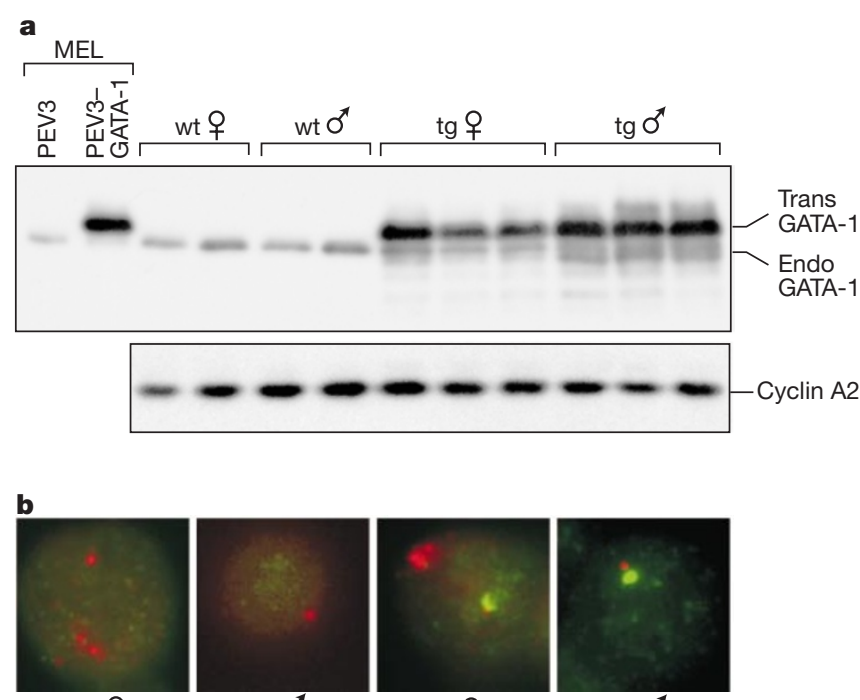

wt +

wto

$\operatorname{tg}$ 우

$32 \pm 2$
$(n=3)$

$\operatorname{tg} \sigma$

$66 \pm 3$
$(n=3)$

$\%$ Trans GATA- $1^{+}$

\begin{tabular}{|c|c|c|c|c|c|}
\hline & & & \%Erythroid & \multicolumn{2}{|c|}{$\%$ lacZ $Z^{+}$(of erythroid) } \\
\hline \multicolumn{3}{|c|}{$\underset{(n=5)}{\text { wt male }}$} & $85 \pm 2$ & \multicolumn{2}{|c|}{$0.5 \pm 0.2$} \\
\hline \multicolumn{3}{|c|}{$\begin{array}{c}\mathrm{Btk}^{\mathrm{lacz} /+} \text { female } \\
(n=7)\end{array}$} & $84 \pm 3$ & \multicolumn{2}{|c|}{$9.0 \pm 3.3$} \\
\hline \multicolumn{3}{|c|}{$\begin{array}{l}\text { GATA- } 1 \text { tg male } \\
\qquad(n=7)\end{array}$} & $79 \pm 3$ & \multicolumn{2}{|c|}{$1.3 \pm 0.3$} \\
\hline \multicolumn{3}{|c|}{$\begin{array}{c}\text { GATA-1 tg Btk } \\
(n=9)\end{array}$} & $85 \pm 2$ & \multicolumn{2}{|c|}{$9.9 \pm 2.1$} \\
\hline $\begin{array}{l}\text { \%lacz } \\
\text { staining }\end{array}$ & \multicolumn{2}{|c|}{$\begin{array}{c}\text { Erythroid } \\
\text { Large } \quad \text { Medium }\end{array}$} & B-cell & $\begin{array}{l}\text { Granulocytic } \\
\text { lineage }\end{array}$ & $\begin{array}{l}\text { Monocytic } \\
\text { lineage }\end{array}$ \\
\hline wt & 3 & 3 & 1 & 6 & 1 \\
\hline \multicolumn{6}{|c|}{$\mathrm{Btk}^{\mid a c z /+}$ male } \\
\hline No. 1 & 55 & 19 & 81 & 63 & 92 \\
\hline No. 2 & 53 & 16 & 90 & 61 & 91 \\
\hline \multicolumn{6}{|c|}{$\mathrm{Btt}^{1 / a C Z /+}$ female } \\
\hline No. 1 & 20 & 7 & 31 & 33 & 45 \\
\hline No. 2 & 23 & 7 & 39 & 27 & 46 \\
\hline No. 3 & 24 & 9 & 37 & 25 & 44 \\
\hline \multicolumn{6}{|c|}{$\begin{array}{l}\text { GATA-1 tg } \\
\text { Btk }^{\text {lacZ/ } /+ \text { female }}\end{array}$} \\
\hline No. 1 & 35 & 12 & 48 & 34 & 56 \\
\hline No. 2 & 26 & 9 & 37 & 30 & 46 \\
\hline No. 2 & 24 & 7 & 35 & 22 & 39 \\
\hline
\end{tabular}

Figure 2 GATA-1 transgene is subject to X-inactivation. a, Western blot of nuclear extracts from 13.5-d.p.c. fetal livers, with anti-GATA-1 antibody N6. DMSO-induced control (PEV3) and GATA-1 overexpressing (PEV3-GATA-1) MEL cell samples are included. Positions of myc-tagged transgene-derived GATA-1 (trans GATA-1) and endogenous GATA-1 (endo GATA-1) are indicated. Cyclin A2 was used as a loading control. b, RNA FISH on 12.5-d.p.c. disaggregated fetal liver cells. Cells were stained for GATA-1 (green) and Xist (red). Representative cells are shown. The percentage of transgene-derived GATA-1 positive cells, number of embryos and standard deviations are indicated. c, Percentage of erythroid cells and percentage of lac $Z^{+}$erythroid cells in 13.5d.p.c. fetal livers from female GATA-1 transgenic mice mated to Btk ${ }^{l a c Z}$ males. Number of embryos and standard deviations are indicated. $\mathbf{d}$, Percentage of lac $Z^{+}$staining cells in haematopoietic lineages of 6-week-old mice. Erythroid cells are arbritrarily divided into large and medium size according to the forward scatter (FSC) value. Note that GATA-1 transgenic $B t k^{\text {lacZl+ }}$ female no. 1 which expresses lacZ in a high number of erythroid precursors also expresses lacZin a higher than expected number of cells in the B-cell and monocytic lineages. This reflects the normal variance of the binomial distribution of $X$ inactivation balance in early pluripotent precursors. 
being non-transgenic. The phenotypically male transgenic animal contained two X chromosomes (one carrying the transgene) and one Y chromosome (data not shown). Chimaeras generated from four other ES cell clones containing autosomal transgene integrations failed to give germline transmission.

We mated transgenic females and examined their progeny. Transgenic females were indistinguishable from wild-type littermates. Male transgenics were anaemic from 12.5 d.p.c. and dead by 14.5 d.p.c. (Fig. 1a, b). Back-crossing GATA-1 overexpressing females to FVB males for eight generations gave no viable transgenic males (excluding the XXY male). At 13.5 d.p.c., the number of enucleated erythrocytes relative to nucleated erythrocytes was reduced more than threefold in transgenic males compared with controls, showing that definitive erythropoiesis is inhibited (Fig. 1c). The fetal liver of transgenic male embryos, the site of definitive erythropoiesis at 13.5 d.p.c., was normal in size and cell number and contained similar numbers of apoptotic cells (terminal deoxyribonucleotide transferase (TdT)-mediated dUTP nick end labelling (TUNEL) assay; data not shown) compared with controls; however, transgenic male fetal livers contained significantly more early basophilic erythroid precursors and fewer late benzidine-positive cells (Fig. 1c), confirming that erythropoiesis is defective in fetal liver. Unexpectedly, female transgenics displayed no alteration in the morphology of cells in the fetal liver and had normal numbers of enucleated erythrocytes at this stage (Fig. 1c). Expression of putative GATA- 1 target genes such as $\alpha$-globin was unchanged in female transgenics, as RNA FISH detection of $\alpha$-globin nascent transcripts on 13.5-d.p.c. fetal liver cells showed a normal number of cells transcribing $\alpha$-globin (72\% compared with 73\% in controls). Furthermore, co-staining showed that half of these cells were positive for transgene-derived GATA-1 transcripts (data not shown), suggesting that the transgene is sensitive to X-inactivation.

Consistent with this interpretation, western blot analysis gave a higher level of transgene-derived GATA-1 protein in male versus female transgenic embryos (Fig. 2a). RNA FISH using a GATA-1 probe showed that at 12.5 d.p.c., $66 \%$ of transgenic male fetal liver cells were positive for transgene-derived GATA-1 nascent transcripts (appearing as a bright nuclear dot), whereas 32\% of transgenic female cells were GATA-1 positive (Fig. 2b). This method did not detect endogenous GATA-1 transcripts. Co-staining for Xist RNA showed a single punctate signal in male fetal liver cells, corresponding to transcription from the Xist allele on the active X chromosome. Female cells also contained a larger area of accumulated Xist RNA on the inactive X chromosome (or Barr body) ${ }^{10,11}$. Apparent co-localization of Barr body and GATA-1 signals occurred in less than $5 \%$ of double positive cells (Fig. 2b, and data not shown), confirming that male transgenics express the transgene pancellularly and females heterocellularly in response to X-inactivation. Survival of transgenic mice was not dependent on being female per $s e$, as a transgenic XXY male (where X-inactivation occurs ${ }^{7}$ ) was

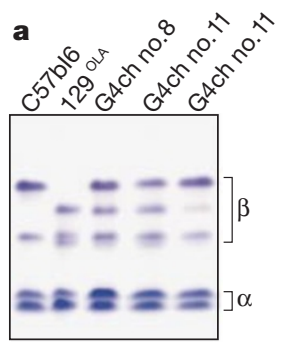

b

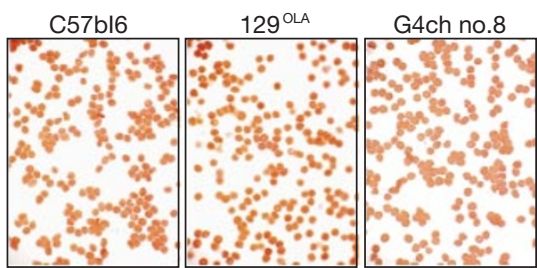

Figure 3 Cells overexpressing GATA-1 contribute to erythroid lineage in adult chimaeric mice. a, Triton-acid-urea gel of lysed blood from C57bl6 (host-blastocyst, Hb single), $129^{\text {OLA }}$ (ES cell strain, Hb diffuse) or clone G4-derived chimaeras (G4ch nos 8, 11 and 14). Indicated are the positions of the $\alpha$-type $(\alpha)$ and $\beta$-type globin ( $\beta$ ) chains. $\mathbf{b}$, Morphology of the blood derived from C57bl6, $129^{\mathrm{OLA}}$ and G4 chimaera no. 8 mice. viable. One might argue that the observed phenotype arises from the X-chromosomal integration event itself; however, overexpression of the tamoxifen-inducible GATA-1-LBD in mice inhibited erythroid differentiation independent of the integration site. GATA$1-\mathrm{LBD}$ accumulated to lower levels than the protein derived from PEV3-GATA-1 and consequently induced a milder phenotype (15\% reduction compared with a $60 \%$ reduction in the proportion of differentiated erythroid cells in a CFU-E assay, data not shown).

To examine the relative contribution of GATA-1-overexpressing cells to the erythroid lineage, we bred transgenic females with males containing a lac $Z$ gene insertion in the $\mathrm{X}$-inactivation sensitive Bruton's tyrosine kinase $\left(\mathrm{Btk}^{\text {lac } Z}\right)$ locus ${ }^{12}$. We found the same number of lac $^{+}$erythroid cells in the fetal livers of 13.5 d.p.c. Btk $^{\text {lacZ/+ }}$ and compound Btk ${ }^{\text {lac } Z+} /$ GATA-1 transgenic females (Fig. 2c). Adult Btk ${ }^{\text {lac } Z}$ males or females expressed lac $Z$ in $50 \%$ or $25 \%$ of large erythroid precursors in the bone marrow, respectively. Compound Btk ${ }^{\text {lac } Z+} /$ GATA-1 transgenic females also expressed lac $Z$ in $25 \%$ of large erythroid precursors (Fig. 2d). Thus, there is a normal representation of cells with an active lac $Z$ gene in the erythroid compartment of GATA-1-overexpressing females throughout development. We conclude that there is no selection for or against GATA-1-overexpressing cells in females. As these females generate normal numbers of definitive erythrocytes, the GATA-1-overexpressing cells must be differentiating normally in

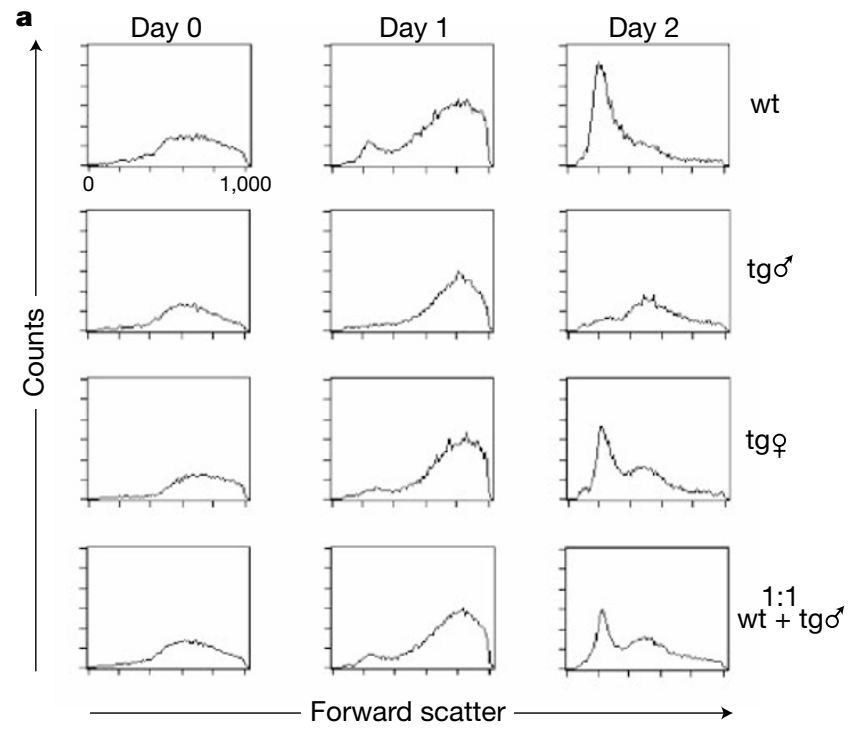

b

\begin{tabular}{|c|ccc|}
\hline \multirow{2}{*}{$\begin{array}{c}w t \\
(n=9)\end{array}$} & \multicolumn{3}{|c|}{$\%$ Dead cells (of erythroid) } \\
\cline { 2 - 4 } $\begin{array}{c}\text { Day 0 } \\
\text { GATA-1 tg male } \\
(n=5)\end{array}$ & $9 \pm 2$ & $18 \pm 2$ & $15 \pm 6$ \\
$\begin{array}{c}\text { GATA-1 tg male } \\
(n=4)\end{array}$ & $11 \pm 3$ & $37 \pm 4$ & $42 \pm 7$ \\
& $13 \pm 7$ & $27 \pm 3$ & $29 \pm 3$ \\
\hline
\end{tabular}

Figure 4 GATA-1 overexpressing CFU-Es fail to differentiate and undergo apoptosis in vitro. $\mathbf{a}$, Representative histogram plots of FSC (indicating relative cell size) of viable erythroid cells from CFU-E assays performed on disaggregated fetal liver cells of 13.5d.p.c. embryos. Cells harvested before (day 0), and after $24 \mathrm{~h}$ (day 1) and $48 \mathrm{~h}$ (day 2) of culture. Shown is the curve obtained by mixing transgenic male and wild-type samples in a 1:1 ratio after different periods of culture. $\mathbf{b}$, Percentage of dead erythroid cells in same samples shown in a. Owing to a background of dead cells with a FSC of less than 327 (using our instrument settings), present in all CFU-E samples, cells with a FSC of less than 327 were excluded from this analysis. 
vivo. To confirm that GATA-1-overexpressing cells contribute to the adult erythrocyte pool, chimaeric animals were generated with clone G4 cells (which are male and express the GATA-1 transgene pancellularly). These cells contributed up to $50 \%$ of the erythrocytes, as assayed by globin chain isoform analysis (Fig. 3a) and confirmed by glucose phosphate isomerase analysis (data not shown). These cells were morphologically normal (Fig. 3b). Furthermore, analysis of the blood of female transgenic mice showed no effect on other blood cell parameters, including red cell number, cell volume and haemoglobin content (data not shown).

To determine which differentiation stage is affected in the transgenic males, we carried out burst-forming unit-erythroid (BFU-E, reflecting early committed erythroid progenitors) and colony-forming unit-erythroid (CFU-E, reflecting a later stage in erythroid differentiation) assays. The same number of colonies in BFU-E and CFU-E assays were formed from both wild-type and transgenic 12.5-d.p.c. and 13.5-d.p.c. fetal livers (data not shown). CFU-E colonies develop from single cells ${ }^{13}$ and do not require accessory cells to form ${ }^{14}$, so the effect of GATA-1 overexpression on female transgenic precursors when no longer in close contact with non-overexpressing cells could be addressed. In male transgenic CFU-E colonies, the production of small late differentiated erythroid cells is inhibited (Fig. 4a), and after $24 \mathrm{~h}$ about $40 \%$ of erythroid cells were dead, compared with $20 \%$ in wild-type cultures (Fig. 4b). Female transgenic CFU-E cultures had an intermediate phenotype (Fig. 4a, b), identical to that found when wild-type and male transgenic cells were mixed before or after culture at a 1:1 ratio. This shows that female GATA-1-overexpressing erythroid precursors are intrinsically defective and behave identically to transgenic male erythroid precursors when removed from the fetal liver.

Gene function is 'cell autonomous' when a cell displays a phenotype that corresponds to its genotype, regardless of the genotype of surrounding cells. Gene function is defined as 'cell nonautonomous' when a cell exhibits a phenotype that does not correspond to its genotype ${ }^{15}$. In mosaics (that is, female transgenics and male chimaeras), the phenotype of GATA-1 transgenic cells is wild type. The function of the GATA-1 transgene is therefore cell nonautonomous. The conventional interpretation would be that erythroid cells overexpressing GATA-1 are normal and that the GATA-1 transgene causes a defect in a non-erythroid cell normally supporting erythropoiesis. If so, then all erythroid precursors in female transgenics would behave identically in vivo and in vitro; however, this is not the case (Fig. 4). Thus, the conventional interpretation of cell nonautonomy is incorrect.

Perhaps the mutant erythroid cells produce a negative factor inhibiting differentiation, and this is diluted in mosaics. To be cell nonautonomous, however, expression of such a negative signalling factor would have to be the only defect in the cells overexpressing GATA-1. Considering the biochemical effects of GATA-1 overexpression in erythroid cells $s^{6,16,17}$, this is unlikely. As GATA-1-overexpressing erythroid cells are intrinsically defective, they must be responding to a signal reversing these defects in mosaics. We therefore propose that wild-type cells produce a positive factor activating the differentiation of GATA-1 overexpressing cells. We tentatively name this activity 'red cell differentiation signal' or REDS. The cells producing REDS must be absent or reduced in transgenic males. Definitive erythropoiesis occurs in erythroblastic islands ${ }^{18}$. These contain a central macrophage surrounded by erythroid cells at all stages of maturation, with immature cells close to the macrophage and mature cells near the edge of the island ${ }^{18,19}$ (Fig. 5). The obvious candidate source of REDS is mature erythroid cells, as this is the only cell population clearly reduced in the transgenic males. Merely allowing wild-type fetal liver cells to contact cells overexpressing GATA-1 by mixing them in liquid culture does not restore differentiation to the latter (data not shown), indicating that disruption of the structure of the erythroblastic island also disrupts REDS activity. We suggest that mature erythroid cells on the periphery of the island are the source of REDS. In mosaics, late erythroid cells overexpressing GATA-1 are juxtaposed with REDS-producing wild-type mature cells in the same erythroblastic island and/or the neighbouring island. This overcomes the defects induced by high GATA-1 levels and allows the final stages of erythroid maturation to proceed. In male transgenic mice there is no such juxtaposition. Death ligands expressed by mature erythroid cells can induce the degradation of GATA-1

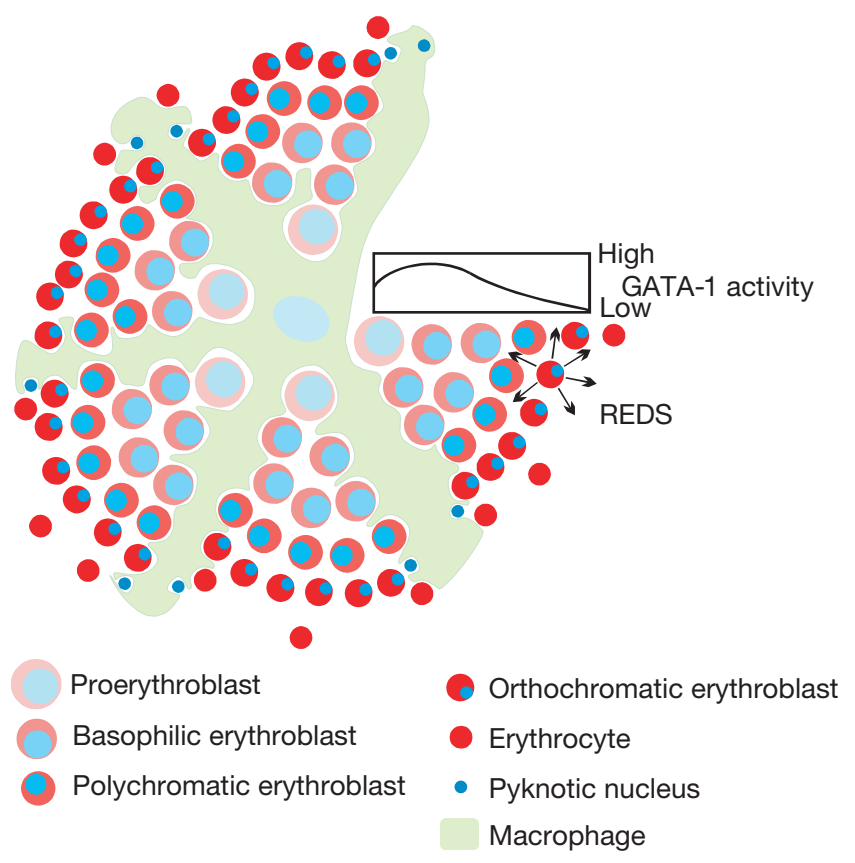

Figure 5 A simplified model of the erythroblastic island. The position of the central macrophage and the arrangement of the erythroid precursors (as indicated by the key) within the macrophage's cytoplasmic extensions are shown. The processes of pyknosis, enucleation and phagocytosis of expelled pyknotic nuclei are represented. Arrows indicate the putative signal REDS, being produced by late differentiated erythroid cells. Graph indicates the proposed process of GATA-1 regulation late in the differentiation process. 
(ref. 20). It is therefore possible that death ligands are a component of REDS. In support of this, death ligands partially reverse the effect of GATA-1 overexpression in vitro (data not shown).

There is one precedent for a signalling mechanism similar to the one that we propose. Caenorhabditis elegans larvae null for the IGF receptor homologue DAF-2 enter a state of diapause rather than developing into adulthood; however, DAF-2 null mosaic animals can become adult with all cells differentiating into adult tissues ${ }^{15}$. Significantly, an adult phenotype is not associated with an obligatory requirement for DAF-2 activity in a particular cell. Consequently, secondary signals may operate to ensure that all cells adopt the same developmental fate ${ }^{15}$. Furthermore, our observations have important implications in interpreting other cell-nonautonomous defects. For example, loss of the retinoblastoma protein results in a cellnonautonomous inhibition of erythropoiesis. In accordance with the conventional interpretation of cell nonautonomy, it was concluded that retinoblastoma protein null erythroid cells are normal and that retinoblastoma protein function is required in stromal cells supporting erythropoiesis ${ }^{21,22}$. This conclusion may be incorrect, as transplantation studies suggest that retinoblastoma protein is required in erythroid cells ${ }^{23}$. This discrepancy remains unexplained; however, one resolution may be that the effect of retinoblastoma protein loss in erythroid cells is reversed by a signal supplied by wildtype cells, similar to the one that restores the normal differentiation of erythroid cells overexpressing GATA-1.

\section{Methods}

\section{Plasmids, probes and primers}

Plasmids PEV3-GATA-1 and PEV3 have been described ${ }^{24}$. Details of the cloning steps to produce the puromycin resistant version of PEV3-GATA-1 are available on request. Integration of PEV3-GATA-1 in ES cells and mice was screened by Southern blot using a 1-kilobase (kb) internal probe corresponding to the $5^{\prime}$ end of the GATA-1 minigene. DNA FISH and RNA FISH was performed using a FITC-labelled 4.3-kb fragment spanning exon 2 to exon 6 of the GATA-1 gene, a Texas-Red labelled 21-kb human $\beta$-globin LCR probe and a Texas-Red labelled 6.5-kb fragment corresponding to the Xist RNA (a gift from N. Brockdorff). Embryos were sexed by PCR using primers specific for the Zfy gene ${ }^{25}$.

\section{Western blotting}

Nuclear extracts were prepared as described ${ }^{26}$. Each sample $(5 \mu \mathrm{g})$ was subject to electrophoresis through a $10 \%$ SDS polyacrylamide gel, transferred onto nitrocellulose and probed with anti-GATA-1 antibody N6 (Santa Cruz) or anti-cyclin A2 antibody C-19 (Santa Cruz) and an appropriate secondary antibody before detection using chemiluminesence.

\section{ES cells}

The puromycin resistant version of PEV3-GATA-1 was linearized with $P v u 1$ and electroporated into $129^{\text {OLA }}$-derived ES cells as described ${ }^{27}$ and individual clones selected in $1 \mu \mathrm{g} \mathrm{ml}^{-1}$ puromycin.

\section{Mice}

Chimaeric mice were generated by injecting ES cell clones generated as above into C57bl6 blastocysts. Chimeras were then bred with wild-type FVB males and screened by coat colour for germ-line transmission. Transgenic females were then mated to FVB males or $\mathrm{Btk}^{\text {lac } Z}$ males and sacrificed during gestation or allowed to go to term.

\section{Blood and fetal liver cell analysis}

Blood and/or disaggregated fetal livers were collected from embryos or adults and prepared on slides by cytocentrifugation. Slides were stained with neutral benzidine and a modified Giemsa-like stain.

\section{Haemoglobin analysis}

Globin chain representation in chimaeric animals was analysed as described ${ }^{22}$.

\section{DNA and RNA FISH}

DNA FISH was done as described ${ }^{28}$. RNA FISH was performed on disaggregated fetal liver cells as described ${ }^{29}$.

\section{CFU-E assay}

CFU-E assays were done as described ${ }^{30}$. Fetal livers were disaggregated into single cells by passage through a $100-\mu \mathrm{m}$ mesh and plated at a density of $3 \times 10^{5}$ cells per $\mathrm{ml}$ in methylcellulose containing $1 \mathrm{unit} \mathrm{ml}^{-1}$ Epo. Colonies were grown for times indicated and then collected and washed with PBS to remove residual methylcellulose before staining.

\section{FACS analysis}

Single-cell suspensions of bone marrow, fetal livers and cultured cells were prepared as above, stained and analysed by FACS as described ${ }^{14}$ with $5 \times 10^{4}$ events taken per sample. We used the following antibodies and stains: R-PE-conjugated TER119 antibody (Pharmingen), 7-aminoactinomycin-D (7AAD, Molecular Probes BV), fluoroscein-di- $\beta$-Dgalactopyranoside (FDG, Molecular Probes BV), biotin-conjugated ER-MP20 antibody, cychrome-conjugated CD45R/B220 (Pharmingen) and Tricolor-streptavidin secondary antibody (Calatag Laboratories). Cell populations were divided as follows: non-viable $\left(7 \mathrm{AAD}^{+}\right)$, erythroid $\left(\mathrm{TER} 119^{+}\right)$, large erythroid (TER $\left.119^{+} / \mathrm{FSC}^{\text {high }}\right)$, medium-sized erythroid (TER $\left.119^{+} / \mathrm{FSC}^{\text {medium }}\right)$, B-cell lineage (B220 $\left./ \mathrm{ER}^{+} \mathrm{MP} 20^{-} / \mathrm{TER}^{-}\right)$, granulocytic (ERMP20 $0^{+} /$TER $119^{-}$) and monocytic (ER-MP20 $0^{\text {high }} /$ TER $119^{-}$).

Received 13 March; accepted 11 May 2000

1. Pevny, L. et al. Erythroid differentiation in chimaeric mice blocked by a targeted mutation in the gene for transcription factor GATA-1. Nature 349, 257-260 (1991).

2. Weiss, M. J., Keller, G. \& Orkin, S. H. Novel insights into erythroid development revealed through in vitro differentiation of GATA-1 embryonic stem cells. Genes Dev. 8, 1184-1197 (1994).

3. Rossant, J. \& Spence, A. Chimera and mosaics in mouse mutant analysis. Trends Genet. 14, 358-363 (1998).

4. Weiss, M. J. \& Orkin, S. H. Transcription factor GATA-1 permits survival and maturation of erythroid precursors by preventing apoptosis. Proc. Natl Acad. Sci. USA 92, 9623-9627 (1995).

5. Takahashi, S. et al. Role of GATA-1 in proliferation and differentiation of definitive erythroid and megakaryocytic cells in vivo. Blood 92, 434-442 (1998).

6. Whyatt, D. J. et al. The level of the tissue-specific factor GATA-1 affects the cell-cycle machinery. Genes Funct. 1, 11-24 (1997).

7. Kuroda, M. I. \& Meller, V. H. Transient Xist-ence. Cell 91, 9-11 (1997).

8. Fujiwara, Y., Browne, C. P., Cunniff, K., Goff, S. C. \& Orkin, S. H. Arrested development of embryonic red cell precursors in mouse embryos lacking transcription factor GATA-1. Proc. Natl Acad. Sci. USA 93, 12355-12358 (1996).

9. Tsai, F. -Y., Browne, C. P. \& Orkin, S. H. Knock-in mutation of transcription factor GATA-3 into the GATA-1 locus: partial rescue of GATA-1 loss of function in erythroid cells. Dev. Biol. 196, 218-227 (1998).

10. Panning, B., Dausman, J. \& Jaenisch, R. X chromosome inactivation is mediated by Xist RNA stabilization. Cell 90, 907-916 (1997).

11. Sheardown, S. A. et al. Stabilization of Xist RNA mediates initiation of X chromosome inactivation. Cell 91, 99-107 (1997).

12. Hendriks, R. W. et al. Inactivation of Btk by insertion by insertion of lac Z reveals defects in B cell development only past the pre-B cell stage. EMBO J. 15, 4862-4872 (1996).

13. Cormack, D. Time-lapse characterization of erythrocytic colony-forming cells in plasma cultures. Exp. Hematol. 4, 319-327 (1976).

14. Sawada, K., Krantz, S. B., Dessypris, E N. Koury, S. T. \& Sawyer, S. T. Human colony-forming unitserythroid do not require acessory cells but do require direct interaction with insulin-like growth factor 1 and/or insulin for erythroid development. J. Clin. Invest. 83, 1701-1709 (1989).

15. Apfeld, J. \& Kenyon, C. Cell nonautonomy of C. elegans daf-2 function in the regulation of diapause and life span. Cell 95, 199-210 (1998).

16. Dubart, A., Romeo, P. H., Vainchenker, W. \& Dumenil, D. Constitutive expression of GATA-1 interferes with the cell-cycle regulation. Blood 87, 3711-3721 (1996).

17. Briegel, K. et al. Regulation and function of transcription factor GATA-1 during red blood cell differentiation. Development 122, 3839-3850 (1996).

18. Bessis, M., Lessin, L. S. \& Beutler, E. in Hematology (eds Williams, W. J., Beutler, E., Erslev, A. J. \& Lichtman, M. A.) 257-279 (McGraw-Hill, New York, 1983).

19. Bernard, J. The erythroblastic island: past and future. Blood Cells 17, 5-14 (1991).

20. De Maria, R. et al. Negative regulation of erythropoiesis by caspase-mediated cleavage of GATA-1. Nature 401, 489-493 (1999).

21. Williams, B. O. et al. Extensive contribution of Rb-deficient cells to adult chimeric mice with limited histopathological consequences. EMBO J. 13, 4251-4259 (1994).

22. Maandag, E. C. et al. Developmental rescue of an embryonic-lethal mutation in the retinoblastoma gene in chimeric mice. EMBO J. 13, 4260-4268 (1994).

23. Hu, N., Gulley, M. L., Kung, J. T. \& Lee, E. Y.-H. Retinoblastoma gene deficiency has mitogenic but not tumorigenic effects on erythropoiesis. Cancer Res. 57, 4123-4129 (1997).

24. Elefanty, A. G., Antoniou, M., Custodio, N., Carmo-Fonseca, M. \& Grosveld, F. G. GATA transcription factors associate with a novel class of nuclear bodies in erythroblasts and megakaryocytes. $E M B O \mathrm{~J} .15$, 319-333 (1996).

25. Nagamine, C. M., Chan, K. M., Kozak, C. A. \& Lau, Y. F. Chromosome mapping and expression of a putative testis-determining gene in the mouse. Science 243, 80-83 (1989).

26. Andrews, N. C. \& Faller, D. V. A rapid micropreparation technique for extraction of DNA-binding proteins from limiting numbers of mammalian cells. Nucleic Acids Res. 19, 2499 (1991).

27. Pandolfi, P. P. et al. Targeted disruption of the GATA3 gene causes severe abnormalities in the nervous system and in fetal liver haematopoiesis. Nature Genet. 11, 40-44 (1995).

28. Mulder, M. P. et al. Positional mapping of loci in the DiGeorge critical region at chromosome 22q11 using a new marker (D22S183). Human Genet. 96, 133-141 (1995).

29. Wijgerde, M., Grosveld, F. \& Fraser, P. Transcription complex stability and chromatin dynamics in vivo. Nature 377, 209-213 (1995).

30. Wong, P. M. C., Chung, S. W., Chui, D. H. K. \& Eaves, C. J. Properties of the earliest clonogenic hemopoietic procursors to appear in the developing murine yolk sac. Proc. Natl Acad. Sci. USA 83, 3851-3854 (1986).

\section{Acknowledgements}

We thank R. Bernards for his critical evaluation, discussions and materials contributing to this work. We also thank M. von Lindern, T. Verkerk, V. Lui, R. Delwel, S. Verbakel, G. Zafarana, N. Gillemans, D. Meijer, T. Stijnen, E. Dzierzak, E. Noteboom, R. Kerkhoven, J.-H. Dannenberg, H. te Riele and members of R. Bernards' laboratory for advice, 
assistance and materials at various stages of the project. D.W. is supported by a long-term EMBO Fellowship. F.L. is supported by NWO (Netherlands). R.H. is supported by KNAW (Netherlands). NWO (Netherlands) and the EC supported this work.

Correspondence and requests for materials should be addressed to F.G. (e-mail: grosveld@ch1.fgg.eur.nl).

\section{Different initiation of pre-TCR and $\gamma \delta$ TCR signalling} Claude Saint-Ruf ${ }^{\star}$, Maddalena Panigada $\dagger$, Orly Azogui ${ }^{\star}$,
Pascale Debey $\ddagger$, Harald von Boehmer $₫$ \& Fabio Grassi ${ }^{\dagger}$

* Institut Necker, U INSERM 373, Faculté de Médecine Necker, 156 Rue de Vaugirard, F75730, Paris cedex 15, France

†Unité INRA 806, Muséum National d'Histoire Naturelle, Institut de Biologie Physico-Chimique, 13, Rue Pierre et Marie Curie, 75005 Paris, France

$\$$ Dipartimento di Biologia e Genetica per le Scienze Mediche,

Università degli Studi di Milano, Via Viotti 3/5, 20133 Milano, Italy

$\$$ Harvard Medical School, Dana-Farber Cancer Institute, 44 Binney Street,

Smith 736, Boston, Massachussetts, 02115, USA

Lineage choice is of great interest in developmental biology. In the immune system, the $\alpha \beta$ and $\gamma \delta$ lineages of T lymphocytes diverge during the course of the $\beta$-, $\gamma$ - and $\delta$-chain rearrangement of T-cell receptor (TCR) genes that takes place within the same precursor cell and which results in the formation of the $\gamma \delta \mathrm{TCR}$ or pre-TCR proteins ${ }^{1-3}$. The pre-TCR consists of the TCR $\beta$ chain covalently linked to the pre-TCR $\alpha$ protein, which is present in immature but not in mature $T$ cells which instead express the TCR $\alpha$ chain $^{4,5}$. Animals deficient in pre-TCR $\alpha$ have few $\alpha \beta$ lineage cells but an increased number of $\gamma \delta$ T cells. These $\gamma \delta$ T cells exhibit more extensive TCR $\beta$ rearrangement than $\gamma \delta$ T cells from wild-type mice ${ }^{6,7}$. These observations are consistent with the idea that different signals emanating from the $\gamma \delta$ TCR and pre-TCR instruct lineage commitment ${ }^{8}$. Here we show, by using confocal microscopy and biochemistry to analyse the initiation of signalling, that the pre-TCR but not the $\gamma \delta$ TCR colocalizes with the p56 ${ }^{\text {lck }}$ Src kinase into glycolipid-enriched membrane domains (rafts) apparently without any need for ligation. This results in the phosphorylation of CD3 $\epsilon$ and Zap-70 signal transducing molecules. The results indicate clear differences between preTCR and $\gamma \delta$ TCR signalling.

The analysis by confocal microscopy of pre-TCR $\alpha$ (pT $\alpha)$ distribution in the plasma membrane of pre-TCR expressing thymocytes revealed a punctate staining pattern in contrast to the more diffuse and uniform distribution of CD25 (Fig. 1Aa-c). Peripheral $\alpha \beta \mathrm{T}$ cells and $\gamma \delta$ thymocytes also exhibited a more uniform receptor staining (Fig. 1Ad-g). Quantitation of colocalization of $\mathrm{pT} \alpha$ and TCR $\beta$ chains on the surface of thymocytes revealed a strong positive correlation ${ }^{9}$ (correlation coefficient 0.95 ) and therefore the almost complete colocalization of the long $\mathrm{pT} \alpha$ isoform with the TCR $\beta$ chain in patches of the cell membrane from immature thymocytes (Fig. $1 \mathrm{Ba}-\mathrm{e}$ ). The patchy distribution of the pre-TCR was reminiscent of the distribution on the cell surface of the $\alpha \beta$ TCR after ligand binding ${ }^{10}$, which is caused by crosslinking of the $\alpha \beta$ TCR and subsequent localization into glycolipid-enriched membrane domains (rafts) ${ }^{11-14}$. These rafts contain GPI-linked proteins, Src-like tyrosine kinases and other proteins targeted to rafts through saturated acyl chains ${ }^{15-18}$. As the patchy distribution of the pre-TCR could conceivably be due to localization into rafts, we tested whether the pre-TCR, in the absence of any deliberate ligation, would colocalize with raft components in the membrane of a SCID thymocyte-derived cell line (SCIET.27) that had been transfected with a productive TCR $\beta$ gene and expressed the preTCR on the cell surface (SCB.29) ${ }^{4}$. Co-staining with $\mathrm{GM}_{1}$-binding cholera toxin $\mathrm{B}(\mathrm{CTxB})$ and $\mathrm{pT} \alpha$ antibodies revealed the same clustered distribution of the pre-TCR as observed with thymocytes and colocalization with $\mathrm{GM}_{1}$ (Fig. 2Aa-d). A similar colocalization was also observed with thymocytes (data not shown). These results suggested that a putative pre-TCR ligand on thymic stroma was not essential for the patchy staining and colocalization with $\mathrm{GM}_{1}$.

The pre-TCR clustering was significantly reduced after cholesterol depletion with methyl- $\beta$-cyclodextrin (M $\beta C D$ ) (Fig. 2Ae, f), indicating the requirement for an intact lipid configuration. This suggests that the observed staining pattern was not caused by antibody crosslinking, because lateral mobility of transmembrane proteins is not inhibited by cholesterol depletion ${ }^{19}$. We also transfected the SCIET.27 cell line with a vector encoding a $(\mathrm{V} \beta 8.2 \mathrm{D} \beta 1 \mathrm{~J} \beta 2.6 \mathrm{C} \beta 2)$ TCR $\beta$ chain-enhanced green fluorescent (eGFP) fusion protein and found a clustered distribution of the tagged pre-TCR by confocal microscopy. No such clustering occurred with GFP protein alone (Fig. $2 \mathrm{Ba}-\mathrm{d}$ ). This further ruled out a requirement for pre-TCR crosslinking. (The large area of intracellular staining in Fig. 2Bc may represent internalized receptors).

To assess whether expression of a $\gamma \delta$ TCR would yield a similarly patchy staining, we transfected V $\gamma 1 \mathrm{~J} \gamma 1 \mathrm{C} \gamma 4$ and $\mathrm{V} \delta 7.1 \mathrm{~J} \delta 1 \mathrm{C} \delta$ genes into the same pro-T cell line SCIET.27. Even though the $\gamma \delta$ TCR was expressed at similar levels, the staining was much more homogenous (Fig. 2Be, f).

Genetic evidence implicates $\mathrm{p} 56^{\text {lck }}$ as an essential component in pre-TCR function ${ }^{20}$. We therefore tested whether the pre-TCR would colocalize with $\mathrm{p} 56^{l c k}$ in roughly the same way that it colocalizes with the $\alpha \beta$ TCR after crosslinking ${ }^{21-23}$. We found that
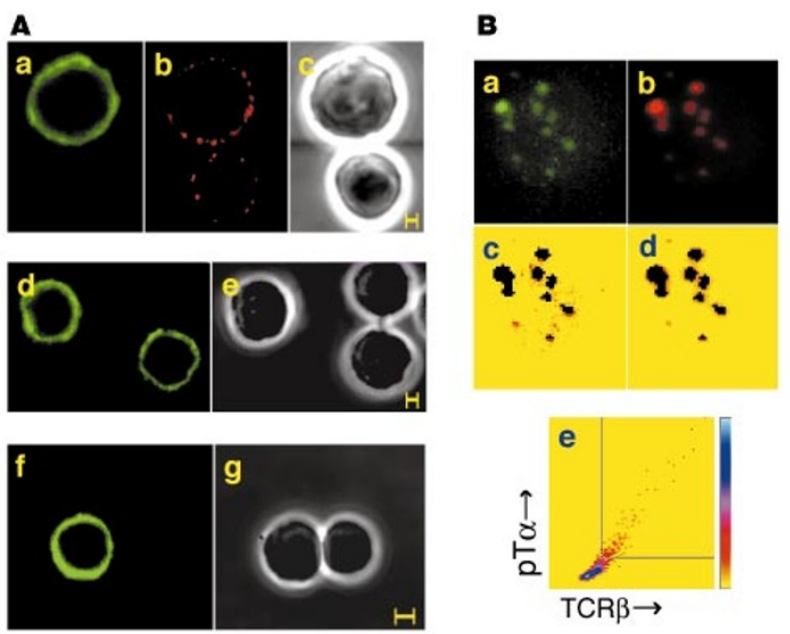

Figure 1 Analysis of the pre-TCR in the cell membrane of thymocytes. A, Punctate pattern of $p T \alpha$ chains on the surface of $\mathrm{CD}^{-} 8^{-}$thymocytes. Co-staining of $\mathrm{CD}^{-} 8^{-}$thymocytes with FITC-conjugated PC-61 (anti-CD25) monoclonal antibody (a) and biotinylated 2F5 (anti-pT $\alpha$ ) monoclonal antibody revealed by streptavidin-TR (b), with phase contrast image (c). Staining of $\gamma \delta$ thymocytes with biotin-labelled GL-3 monoclonal antibody revealed by streptavidin-FITC (d, e). Staining of lymph nodes cells with FITC-conjugated H57-597 monoclonal antibody (f, g). Scale bar, $2 \mu \mathrm{m}$. B, Quantitative colocalization analysis of TCR $\beta$ and full-length $p T \alpha$ chains on the surface of $\mathrm{CD}^{-} 8^{-}$thymocytes. Cells were stained with FITC-conjugated H57-597 (anti-TCR $\beta$ ) and biotin-labelled 2F5 (antipT $\alpha$ ) monclonal antibodies revealed by streptavidin-TR. Spatial distribution of TCR $\beta$ (a) and pT $\alpha$ (b) stainings and corresponding SPIMAC 2D histogram (e). Areas outside the selected region in the $2 \mathrm{D}$ histogram represent the background; the pixels comprised in the region appear in black in the TCR $\beta$ (c) and $p T \alpha(\mathbf{d})$ images and correspond to the green and red dots in $\mathbf{a}$ and $\mathbf{b}$. 